\title{
John E. Cooper and Margaret E. Cooper (eds.): Wildlife forensic investigation-principles and practice
}

\author{
CRC Press, Boca Raton, London, New York, 2013, ISBN: 978-1-4398-1374-4
}

\author{
Michael Tsokos
}

Accepted: 8 October 2013/Published online: 7 November 2013

(C) Springer Science+Business Media New York 2013

This textbook is devoted to a relatively new discipline in the field of forensics: wildlife forensics. With 16 chapters and a comprehensive appendix making a total of more than 700 pages, this book can undoubtedly be regarded as representing the state of the art of wildlife forensics to date.

The vast experience of the John and Margaret Cooper in the field of wildlife forensics builds on many different disciplines coming together. This husband and wife team have spent their life fighting to protect living creatures from criminal and other irresponsible human activities.

With the aid of 26 international experts in their respective fields, the Coopers present all aspects of wildlife forensics. After a short introduction (chapter 1-What is wildlife forensics?), the chapters are devoted to types of wildlife investigation (chapter 2), legislation (chapter 3), application of forensic science to wildlife investigations (chapter 4), wildlife crime scenes (chapter 5), forensic entomology (chapter 6), field techniques (chapter 7), working with live (chapter 8) and dead animals (chapter 9), dealing with samples (chapter 10), genetic methodologies (chapter 11), laboratory work (chapter 12), special considerations and scenarios (chapter 13), collection and submission of evidence (chapter 14), writing reports and appearing in court (chapter 15), and the way forward (chapter 16). My favorite chapter is chapter 13. Sixteen authors have contributed their individual experience to this incredibly interesting chapter with numerous case studies, including identification systems in hunting falcons, welfare issues of captive Asian elephants, illegal killing of wolfs in Eastern Europe, mountain gorilla diseases, bats and turbines, coral imports, etc. The case studies are illustrated with numerous color photographs.

This book is more than just an overview of forensic science relating to animals. This book closes a gap in the literature concerning a scientific approach toward the investigation of wildlife crime. It is essential reading for all those interested in broader forensic issues.
M. Tsokos ( $\square)$

Institute of Legal Medicine and Forensic Sciences,

Charité, Universitätsmedizin Berlin, Turmstr. 21 (Haus N),

10559 Berlin, Germany

e-mail: michael.tsokos@charite.de 